\title{
THE OCCURRENCE OF LACTOBACILLI AND OTHER ACIDOGENIC ORGANISMS IN THE SALIVAS OF SELECTED CARIES-FREE CHILDREN
}

\author{
MARSHALI, L. SNYDER
}

From the Bygienic Laboratory, University of Michigan, Ann Arbor, Michigan

In his monograph of 1889 Miller (1) outlined the now generally accepted view that bacteria in the presence of retained carbohydrate in protected areas of the teeth produce sufficient acid to cause decalcification of the enamel or dental caries. Since that time practically every acid-producing organism of the mouth has been accused at one time or another. However, after Kligler (2) showed the increased presence of $B$. acidophilus in the mouths of individuals with caries, a matter which was confirmed and extended by Rodriguez (3), the bulk of evidence has implicated the lactobacilli. At the Dental School of the University of Michigan an extensive program of research on dental caries is in progress. The Michigan group (4-11) and others have concluded that a lactobacillus, which they specifically call Lactobacillus acidophilus, is the organism to be associated with tooth decay. This taxonomical specificity is vigorously denied by Rettger and his associates (12-16). In addition, there are workers who have either been unable to confirm the correlation of lactobacilli with dental caries or insist that other organisms must be considered because of results with in vitro studies.

As part of the program at Michigan the author, working independently, was asked to examine the laboratory methods of the dental group; that is, first, to test the method for estimating the number of lactobacilli in the saliva; second, to determine whether or not lactobacilli were normal members of the mouth flora; and third, to correlate the cultural results with clinical findings at the beginning, middle, and end of a study on selected caries-free children. This paper covers the methods used to culture the specimens of saliva from these chil-

${ }^{2}$ Supported by a grant from the Horace H. Rackham School of Graduate Studies. 
dren, the tabulation of organisms isolated on a selective medium, and an attempt to analyze the data in terms of the clinical findings. Although the material presented is insufficient to incriminate a species as the bacterial agent in the disease, the data do support the contention that lactobacilli are the bacteria responsible for caries.

Of the acidogenic organisms commonly found in the mouth the streptococci especially received attention from Goadby (17), Clark (18), Baumgartner (19), Kantorowicz (20), Hartzell and Henrici (21), Anderson and Rettger (22), Tunnicliff and Hammond (23), and others. However, since Kligler (2) in 1915 pointed out the increased presence of $B$. acidophilus in the mouths of people with caries, the lactobacilli have been more seriously considered primarily because of their physiological activity; that is, the growth of these forms on carbohydrate media is characterized by the production of large quantities of acid. Furthermore, the lactobacilli not only endure hydrogen-ion concentrations detrimental to the growth of most bacteria but they also multiply in this environment. From the data presented by Rodriguez (3), McIntosh, James and Lazarus-Barlow (23), Bunting et al. (4-11), Jay (24), Rosebury (25), Enright, Friesell and Trescher (26) and others, it is apparent that lactobacilli are generally present in the mouths of individuals with caries and are absent from those with no caries or arrested lesions.

On the other hand, Tucker (27) could find no apparent correlation between the presence of lactobacilli found on tooth scrapings and the dental caries observed in the respective subjects. In 1933, Johnston, Kaake and Agnew (28) stated that L. acidophilus was a member of the normal flora of the mouth in rats and man. In regard to man this statement reflects an impression held by many bacteriologists but for which there is little information in the reviews by Kligler (2), Nizzle (29), and the Cruickshanks (30). However, in 1936 Johnston et al. (31) reversed their earlier conclusions and were able to show a definite correlation between the presence of $L$. acidophilus and dental caries. Yet Anderson and Rettger (16) in 1937 could find lactobacilli in only 12 per cent of 65 patients with caries, and felt that other acidogenic organisms, particularly the streptococci, should not be disregarded. On the basis of examination of the dentin and pulps of 12 extracted teeth and 2 salivas from caries-free people, Tunnicliff and Hammond 
(22) concluded that streptococci were the invaders in dental caries no matter what the predisposing factors.

\section{METHODS}

For the quantitative estimation of the numbers of lactobacilli in the saliva the method of Hadley (32) was closely followed. The specimens were obtained by having the individuals chew sterile wax tablets for 3 minutes and collect the saliva in sterile test tubes during that period. However, instead of diluting the specimens of saliva to 10 c.c. as recommended, measured quantities of saliva were smeared with sterile bent glass rods over acid tomato peptone agar plates, and results estimated in terms of lactobacilli per c.c. of the sample. In addition a portion of the specimen was inoculated into acid glucose broth for a qualitative test. The broth cultures were examined at 48 hours for the presence or absence of pleomorphic Gram-positive rods. On the plates after 96 hours incubation the colonies of lactobacilli appeared as variable but distinct morphological types either alone or associated with colonies of yeasts, streptococci, staphylococci, and sarcines. Those specimens of saliva which showed no lactobacilli on plates or in broth were considered to be negative. On the positive plates the characteristic colonies were examined and counted for the necessary calculations. The occurrence of some negative plates and positive broths was noted, and attributed to the failure of a few lactobacilli to grow on solid media.

Careful examination of each step of this technique showed it to give satisfactory and consistent results. The only place where one is likely to encounter difficulty is in the recognition and enumeration of the colonies of lactobacilli. The total count of the lactobacilli is not only influenced by the marked variation in the colony types, but also by all the objections to selected plate counts; namely, number of viable organisms in the saliva, number growing on selective media, colony representing growth from one or more germs, other types of bacteria, etc. Hence, by tacit admission the method is an estimation of the numbers of lactobacilli in the saliva, and while quantitative in one sense it is primarily relative. Its value lies in successive studies of individuals rather than in a single specimen of saliva; that is, the periodic recording whether lactobacilli are or are not present, sporadically present, or in low or high numbers gives more information than exact figures, especially in view of the statistical significance of errors in counts where 100,000 lactobacilli per c.c. of saliva or more are recorded.

In the present study all the types described by Hadley, Bunting and Delves (9) were seen. The colonies varied from the perfectly smooth white to the matted rough gray type. Microscopically, the Gram- 
positive rods of these colonies appeared as forms scarcely to be distinguished from streptococci to the pleomorphic rods similar to those seen in a milk culture of $L$. acidophilus. Subculturing to acid glucose broth gave heavy flocculent growth; and litmus milk was acidified and coagulated. These studies were not sufficiently extensive to identify the oral lactobacillus as a species; hence, only the generic term "lactobacillus" is used.

\section{SOURCES OF MATERIAL}

Specimens of saliva were obtained from two selected groups of children. One group found to be free from caries by careful dental examination ${ }^{2}$ was from an institution in Maumee, Ohio, where the children have been under observation for nearly a decade by the Michigan group. For the present study the salivas were collected in sterile test tubes under the supervision of a trained member of the school at irregular intervals for 18 months. This material was obtained in the morning and shipped to Ann Arbor where it was cultured in the evening. Cultures were made by smearing 0.4 c.c. saliva over the surface of tomato-peptone agar plates (for the one child with a high lactobacillus count 0.1 c.c. saliva was used after the first test), and placing 0.6 c.c. saliva in acid glucose broth for the qualitative test.

The other group was from two of the Ann Arbor public schools. Here the salivas were obtained by the author at intervals over the 18 month period and the samples plated upon return to the laboratory. The first cultures showed some high lactobacillus counts and others were negative. Therefore, 0.1 c.c. saliva was used for the individuals with numerous lactobacilli and 0.4 c.c. for those subjects with negative or low counts. The amount of saliva used varied, however, from time to time dependent upon the previous determination. For the qualitative tests $0.6-0.9$ c.c. of the samples of saliva were placed in acid glucose broth.

\section{RESULTS}

The numbers of lactobacilli in the salivas of the two selected groups as estimated by the method outlined with a report on the presence or absence of caries at the end of the study is given in Table 1. The

\footnotetext{
2 The author is indebted to Drs. Bunting, Jay, Hard and McCracken for the dental examinations at Maumee and Drs. Hard and Jay for the clinical work in Ann Arbor.
} 
TABLE I

Numbers of lactobacilli in specimens of saliva from selected caries-free children cultured irregularly over an eighteen month period

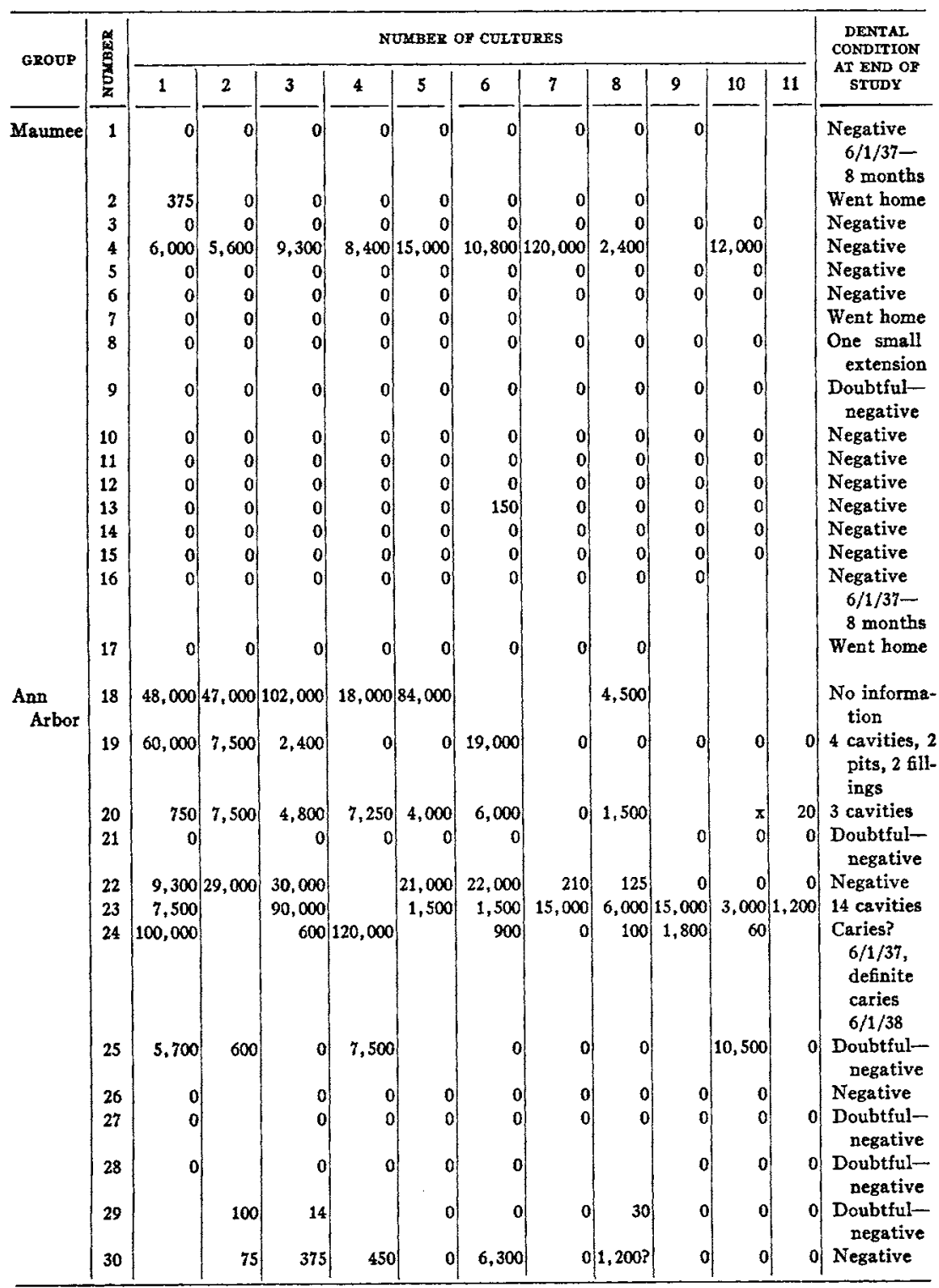


TABLE I-Concluded

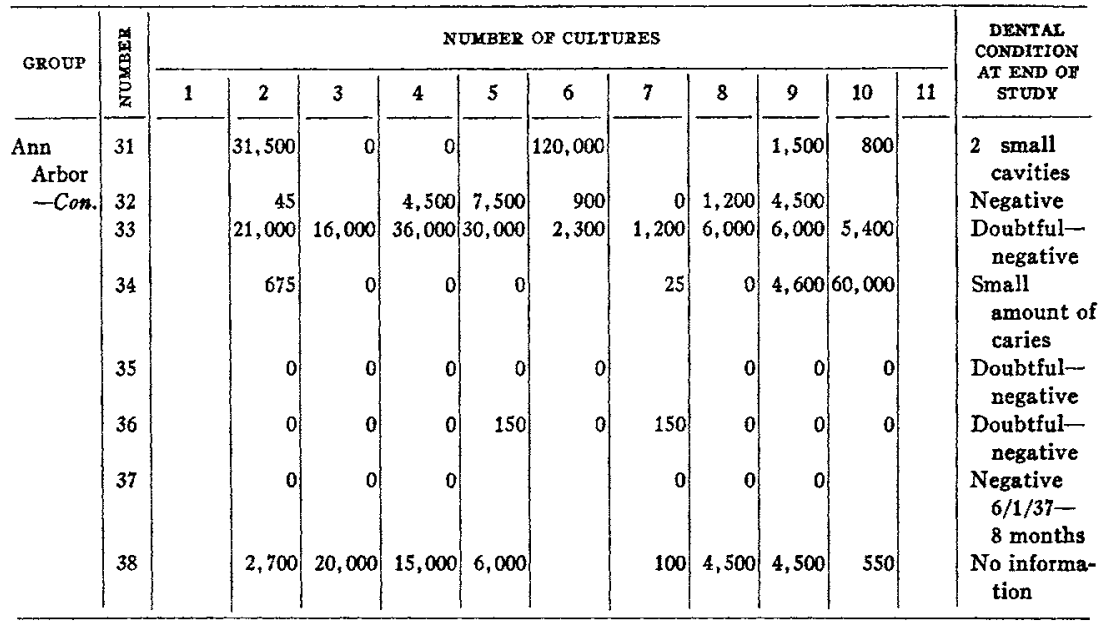

colonies of lactobacilli were identified and counted with the aid of a binocular dissecting microscope and a Frost counting card for a background.

Table I shows that of the 38 children selected as caries-free the salivas of 16 were positive for lactobacilli at the time of the first culture. The significance of this finding in relation to the dental condition will be discussed later. However, as the study progressed, we found in the Maumee group of 17 subjects only 1 who had persistently large numbers of lactobacilli in the saliva. Two other sporadic positives were noted. On the whole the mouths of this group were almost free from lactobacilli and caries, although there were the exceptions of the 1 case with the lactobacilli and no caries and the extension of 1 lesion in a mouth with no lactobacilli. Unfortunately this extension was not found until 3 months after the last specimen from this individual was cultured, and it was possible that the lesion was formed in that period. It is interesting to compare these results with the numbers of lactobacilli and the dental condition at the end of the study of similarly selected caries-free Ann Arbor children of approximately the same ages. Despite the exceptions the data indicate a correlation between the presence and increasing numbers of lactobacilli and the caries present. There were 9 cases listed as "doubtful-negative" for 
caries because the explorer caught at one point during the examination but no lesion was demonstrable. For summation purposes they were

TABLE II

Numbers of yeasts in specimens of saliva from selected caries-free children cullured irregularly over an eighteen month period

\begin{tabular}{|c|c|c|c|c|c|c|c|c|c|c|c|c|c|}
\hline \multirow{2}{*}{ GROUP } & \multirow{2}{*}{ 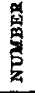 } & \multicolumn{11}{|c|}{ NOMBER OF CULIURES } & \multirow{2}{*}{$\begin{array}{l}\text { DENTAI CONDITION AT END } \\
\text { OF STUDY }\end{array}$} \\
\hline & & 1 & 2 & 3 & 4 & 5 & 6 & 7 & 8 & 9 & 10 & 11 & \\
\hline \multirow[t]{17}{*}{ Maumee } & 1 & 0 & 0 & 0 & 0 & 0 & 0 & of & 0 & 0 & \multirow{3}{*}{\multicolumn{2}{|c|}{25,000}} & \multirow{17}{*}{$\begin{array}{l}\text { Negative } 6 / 1 / 38-8 \text { months } \\
\text { Went home } \\
\text { Negative } \\
\text { Negative } \\
\text { Negative } \\
\text { Negative } \\
\text { Went bome } \\
\text { One small extension } \\
\text { Doubtful-negative } \\
\text { Negative } \\
\text { Negative } \\
\text { Negative } \\
\text { Negative } \\
\text { Negative } \\
\text { Negative } \\
\text { Negative }-6 \text { months } 6 / 1 / 37 \\
\text { Went home }\end{array}$} \\
\hline & 2 & 0 & $\mathbf{0}$ & 0 & 0 & & 39,000 & 0 & 0 & & & & \\
\hline & 3 & 135 & 0 & 0 & 0 & 0 & 6,000 & 0 & 0 & 600 & & & \\
\hline & 4 & 0 & 0 & 0 & 0 & 0 & & 0 & 0 & 0 & 0 & & \\
\hline & 5 & 0 & 0 & 0 & 0 & 0 & 0 & 0 & 0 & 0 & 0 & & \\
\hline & 6 & 0 & 0 & 0 & 0 & 0 & 0 & 0 & 0 & 0 & 0 & & \\
\hline & 7 & 1,500 & 2,400 & 1,150 & 750 & 900 & 3,000 & & & & & & \\
\hline & 8 & 1,200 & 2,100 & 24,000 & 200 & 200 & 200 & 0 & 250 & 0 & 10 & & \\
\hline & 9 & 125 & 150 & 230 & 125 & 100 & 22 & 5 & 0 & 0 & 0 & & \\
\hline & 10 & 10 & 0 & 0 & 5 & 0 & 10 & 0 & 0 & 0 & 0 & & \\
\hline & 11 & 0 & 0 & 0 & 0 & 0 & 0 & 0 & 0 & 0 & 0 & & \\
\hline & 12 & 0 & 0 & 0 & 0 & 0 & 0 & 4 & 0 & 0 & 0 & & \\
\hline & 13 & 0 & 0 & 0 & 0 & 0 & 0 & 36 & 0 & 0 & 0 & & \\
\hline & 14 & 0 & 0 & 0 & 0 & 0 & 0 & 0 & 0 & 0 & 0 & & \\
\hline & 15 & 0 & 0 & 0 & 0 & 0 & 0 & 0 & 0 & of & 0 & & \\
\hline & 16 & 0 & 0 & 0 & o & 0 & 0 & 의 & 0 & 0 & & & \\
\hline & 17 & 0 & 0 & 0 & 0 & o & 0 & 0 & 0 & & & & \\
\hline \multirow{22}{*}{$\begin{array}{l}\text { Ann } \\
\text { Arbor }\end{array}$} & 18 & 0 & 0 & 0 & 0 & of & & & 0 & & & \multirow{8}{*}{$\begin{array}{l}0 \\
0 \\
0 \\
0 \\
0\end{array}$} & tion \\
\hline & 19 & 0 & 0 & 0 & 0 & 0 & 0 & 0 & 0 & 0 & 0 & & 4 cavities, 2 pits, 2 fillings \\
\hline & 20 & & 0 & 0 & 0 & of & 0 & 0 & 0 & 0 & 0 & & 3 cavities \\
\hline & 21 & 0 & & 0 & 0) & 0 & 0 & & & 0 & 0 & & Doubtful-negative \\
\hline & 22 & & 0 & 0 & & 0 & 0 & 0 & 0 & 0 & 0 & & Negative \\
\hline & 23 & 4,950 & & 0 & & 150 & 0 & 0 & 0 & 150 & 85 & & 14 cavities \\
\hline & 24 & 2,700 & & 0 & 0 & & 0 & 0 & 0 & 0 & 0 & & Caries? $6 / 1 / 37$, definite \\
\hline & & & & & & & & & & & & & caries $6 / 1$ \\
\hline & 25 & 0 & 0 & 0 & 0 & & 0 & 요 & 0 & & 0 & c & Doubtful-negative \\
\hline & 26 & 0 & & 0 & 0 & o) & 0 & 0 & 0 & 0 & 0 & & Negative \\
\hline & 27 & 0 & & 0 & 0 & of & 0 & of & 0 & 0 & 0 & $c$ & Doubtful-negative \\
\hline & 28 & 0 & & 0 & o) & 0 & 0 & & & 0 & 0 & & Doubtful-negative \\
\hline & 29 & & 0 & ) & & 0 & 0 & 0 & 0 & 0 & 0 & & Doubtful-negative \\
\hline & 30 & & 0 & 0 & 0 & 4 & 0 & 0 & 0 & 0 & 0 & 0 & Negative \\
\hline & 31 & & 0 & & $0 \mid 20,000$ & & 20,000 & & & 0 & o & & 2 small cavities \\
\hline & 32 & & 0 & & 5 & 0 & 0 & 0 & 0 & 0 & 0 & & Negative \\
\hline & 33 & & 0 & 0 & 0 & 0 & 0 & 0 & 0 & 0 & 0 & & Doubtful-negative \\
\hline & 34 & & 125 & 5 & 28 & 23 & 0 & 10 & 20 & 220 & 0 & & Small amount of caries \\
\hline & 35 & & 0 & of & 0 & 0] & & & 0 & 0 & 0 & & Doubtful-negative \\
\hline & 36 & & 45 & 5 & 0 & 450 & 1,200 & & 100 & 75 & 0 & & Doubtful-negative \\
\hline & 37 & & 0 & 0 & 0 & & & 0 & 0 & 0 & & & Negative $6 / 1 / 37-8$ months \\
\hline & 38 & & 0 & 0 & 0 & 0) & & 0 & 0 & 0 & $\mathbf{0}$ & & No information \\
\hline
\end{tabular}

considered negative, although the necessity for further study of these children is obvious. When these data were subjected to statistical 
TABLE III

Numbers of streptococci in specimens of saliva from selected caries-free children cultured irregularly over an eighteen month period

\begin{tabular}{|c|c|c|c|c|c|c|c|c|c|c|c|c|c|}
\hline \multirow{2}{*}{ GROUP } & \multirow{2}{*}{ 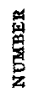 } & \multicolumn{11}{|c|}{ NUMBER OF CULTURES } & \multirow{2}{*}{$\begin{array}{l}\text { DENTAL CONDITION AT } \\
\text { END OF STUDY }\end{array}$} \\
\hline & & 1 & 2 & 3 & 4 & 5 & 6 & 7 & 8 & 9 & 10 & 11 & \\
\hline \multirow[t]{16}{*}{ Maumee } & 1 & 0 & 0 & 130 & 136 & 35 & 0 & 0 & 750 & 0 & & & $\begin{array}{l}\text { Negative } 6 / 1 / 37-8 \\
\text { months }\end{array}$ \\
\hline & 2 & 0 & 0 & 900 & 4,500 & 0 & 0 & 0 & 0 & & & & Went home \\
\hline & 3 & 0 & 0 & 0 & 0) & 0 & 0 & 0 & 0 & 0 & 0 & & Negative \\
\hline & 4 & 0 & 0 & 0 & 0 & 0 & $|11,000|$ & 0 & 0 & 0 & 0 & & Negative \\
\hline & 5 & 0 & 0 & 0 & 3,000 & 0 & 10,000 & 8,250 & 450 & 0 & 30,000 & & Negative \\
\hline & 6 & 0 & 0 & 1,350 & 45 & 180 & $|50,000|$ & 0 & 0 & 0) & 0 & & Negative \\
\hline & 7 & 0 & 0 & 200 & 300 & 600 & 5,250 & & & & & & Went home \\
\hline & 8 & 0 & 0 & 0 & 0 & 0 & 0 & 0 & o. & 0 & 25,000 & & One small extension \\
\hline & 9 & 0 & 0 & 0 & 2,700 & 450 & 3,000 & 0 & 0 & 70 & 0 & & Doubtful-negative \\
\hline & 10 & 0 & 0 & 150 & 150 & 0 & 0 & 0 & 0 & 0 & 0 & & Negative \\
\hline & 11 & 0 & 0 & 0 & 0 & 0 & 0 & 0 & 0 & 0 & 10,000 & & Negative \\
\hline & 12 & 0 & 0 & 150 & 0 & 30 & 9,000 & 0 & 250 & 0 & 50,000 & & Negative \\
\hline & 13 & 0 & 0 & 30,000 & 4,800 & 0 & 0 & 0 & 0 & 0 & 0 & & Negative \\
\hline & 14 & 0 & 0 & 75 & 0 & 225 & 0 & 0 & 0 & 0 & 0 & & Negative \\
\hline & 15 & 0 & 0 & 0 & 0 & 10,500 & 0 & 0 & 0 & 0 & 10,000 & & Negative \\
\hline & 16 & 0 & 0 & 4,000 & 0 & 225 & 0 & 0 & 0 & 0 & & & $\begin{array}{l}\text { Negative } 6 / 1 / 37-8 \\
\text { months }\end{array}$ \\
\hline \multirow{22}{*}{$\begin{array}{l}\text { Ann } \\
\text { Arbor }\end{array}$} & 17 & 0 & 0 & 200 & 125 & 0 & 0 & 0 & 750 & & & & Went home \\
\hline & 18 & 0 & 0 & 0 & 0 & 0 & & & 0 & & & & No information \\
\hline & 19 & 0 & 0 & 0 & 250 & 0 & 0 & 0 & 0 & 0 & 0 & 0 & 4 cavities, 2 pits, 2 fillings \\
\hline & 20 & 0 & 0 & 0 & 0 & 0 & 0 & 0 & 0 & 0 & 0 & 0 & 3 cavities \\
\hline & 21 & 0 & & 0 & 0 & 0 & 0 & & & 600 & 0 & 0 & Doubtful-negative \\
\hline & 22 & 0 & $\mathbf{0}$ & 0 & & 0 & 0 & 0 & 0 & 0 & 0 & 0 & Negative \\
\hline & 23 & 0 & & 0 & & 0 & 0 & 0 & 0 & 0 & 0 & & 14 cavities \\
\hline & 24 & 0 & & 1,800 & 0 & & 0 & 0 & 0 & o) & 0 & & $\begin{array}{c}\text { Caries? } 6 / 1 / 37 \text {, definite } \\
\text { caries } 6 / 1 / 38\end{array}$ \\
\hline & 25 & 0 & 0 & 0 & 0 & & 0) & 0 & 0 & & 0 & 0 & Doubtful-negative \\
\hline & 26 & 0 & & 0 & $12, \infty$ & 0 & 0 & 0 & 0 & 0 & 0 & & Negative \\
\hline & 27 & 0 & & 0 & 0 & 3,000 & 0 & 0 & 0 & 0 & 0 & 0 & Doubtful-negative \\
\hline & 28 & 0 & & 0 & 38 & 0 & & & 0 & 0 & 0 & 0 & Doubtful-negative \\
\hline & 29 & & 0 & 0 & & 0 & 1,500 & 20 & 3,000 & 0 & 0 & 0 & Doubtful-negative \\
\hline & 30 & & 0 & 1,350 & 0 & 0 & 0 & 0 & 4,500 & 0 & 0 & 0 & Negative \\
\hline & 31 & & 0 & o) & 0 & & a) & & & 0 & 0 & & 2 small cavities \\
\hline & 32 & & 0 & & 0) & 0 & 0 & 0 & 6,000 & 0 & 0 & & Negative \\
\hline & 33 & & 0 & 0 & 0 & 0 & 0 & 0 & 0 & 0 & 0 & & Doubtful-negative \\
\hline & 34 & & 0 & 120 & $60,000)$ & 0 & 0 & & 60,000 & 0 & 0 & & Small amount caries \\
\hline & 35 & & 0 & o) & 60,000 & 0 & 0 & & o) & 0 & 0 & & Doubtful-negative \\
\hline & 36 & & 0 & 0 & of & 10 & 0 & & 0 & 150 & 0 & & Doubtful-negative \\
\hline & 37 & & $\mathbf{0}$ & 0 & 450 & & & & 12,000 & 0 & & & Doubtful-negative \\
\hline & 38 & & 0 & 0 & 0 & 0 & & 0 & 7,500 & 0 & 0 & & No information \\
\hline
\end{tabular}

analysis ${ }^{3}$ it was found that the occurrence of lactobacilli in respect to cavity formation was significant, but on the basis of correlation coeffi-

The author is indebted to Dr. Paul Dwyer, Assistant Professor of Mathematics, for assistance in the statistical analysis. 
TABLE IV

Numbers of staphylococci in specimens of saliva from selected caries-free children cultured irregularby over an eighteen month period

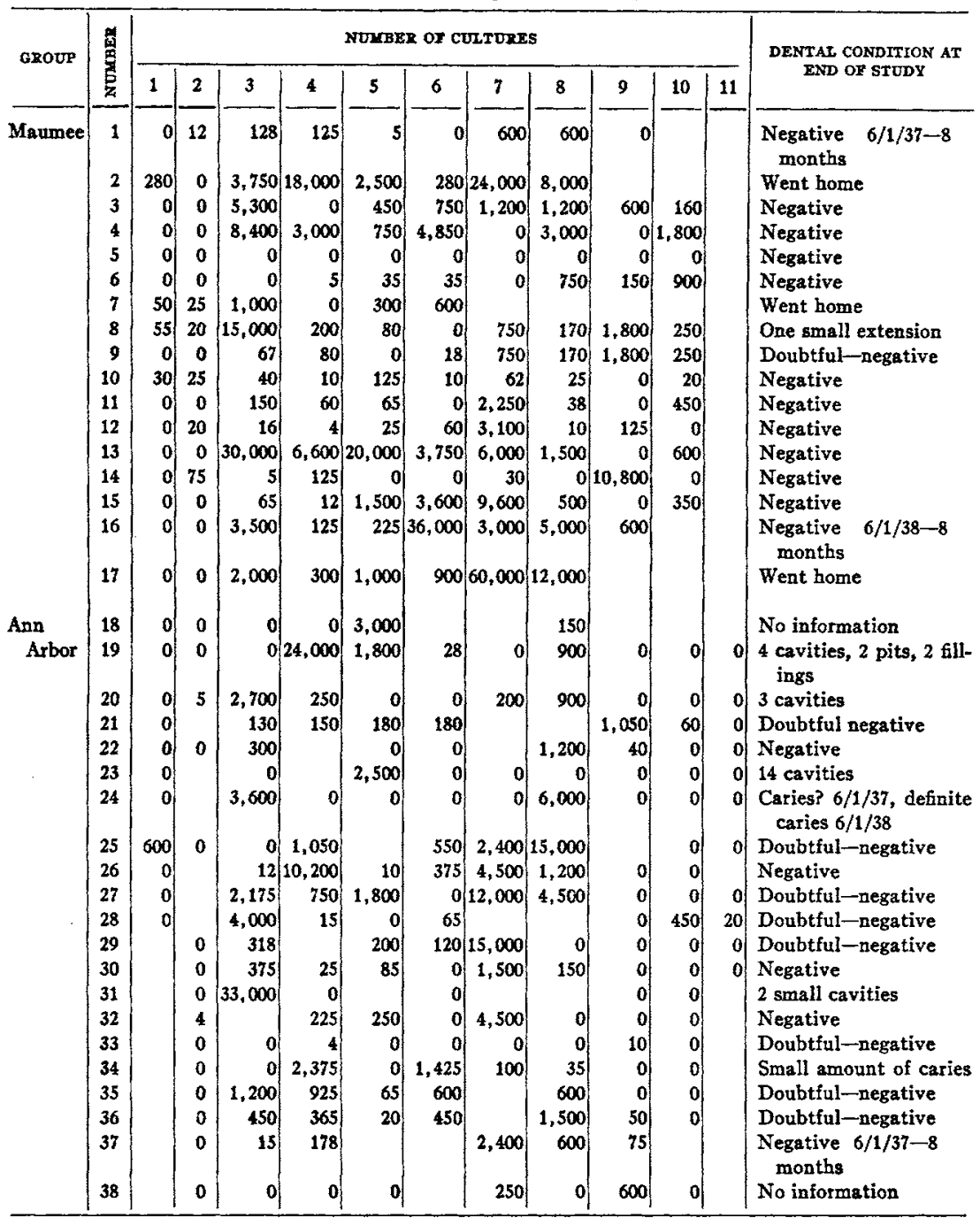

cients it was possible to predict caries for the group only rather than the individual.

There remain for consideration, however, the other acidogenic 
organisms in the mouth. In view of the controversy existing over the role of these forms in dental caries and the fact that there are no extensive and parallel figures on their occurrence and relative numbers, other than lactobacilli, in the saliva as determined by a selective medium over a given period, it seemed highly necessary to tabulate their frequency of appearance on the acid tomato-peptone agar. That the medium was highly selective may be noted by the many culturally negative plates and the very sparse growth of some of the millions of streptococci and other organisms in the saliva. These aciduric forms included the yeasts, streptococci, and staphylococci with the sarcines; their frequency is recorded in Tables II, III, and IV, For the reason of space a group of miscellaneous types is not given.

The data presented in these tables show that the incidence and numbers of streptococci and staphylococci as determined by growth on acid tomato-peptone agar had little if any relation to the caries observed. However, the yeasts warrant some consideration since these forms were frequently present in the salivas of the children with caries. Although the Maumee child with the 1 cavity had apparently significant yeast counts and no lactobacilli, the relation becomes doubtful since the yeasts decreased in number toward the latter part of the study and the lesion was not observed until 3 months after the last specimen was cultured. Similarly, the yeast cells in the salivas of the Ann Arbor children with caries appeared sporadically and seldom in appreciable numbers. These facts, combined with the observation (data in press) that yeasts apparently produce little additional acid in glucose infusion agar at $\mathrm{pH} 5.0$ as measured by changes in the indicator, brom-cresol-green, make it appear that the role of yeasts in dental caries is supplementary to the lactobacilli. These conclusions are supported by statistical analysis with the exception that by the use of correlation coefficients the number of staphylococci in respect to the number of cavities approaches the minimum significant figure $(0.3)$.

\section{DISCUSSION}

To interpret any information obtained by cultural studies it must be remembered that it is not possible to tell whether caries is active or arrested by merely looking in the mouth or examining extracted teeth. 
Only by careful dental examination followed by others at regular intervals over a period of a year when any extension of previous lesions or appearance of new decay can be noted may activity be established. The lack of adequate clinical information eliminates from serious consideration many of the reported bacteriological studies of dental caries. This omission is especially noticeable in the recent papers of Anderson and Rettger (16) and Tunnicliff and Hammond (22). The former found lactobacilli in only 12 per cent of 65 cases selected apparently without sufficient dental information; the latter in their few examinations depended almost entirely on extracted teeth, and assumed caries activity by the presence of cavities. However, where carefully controlled comparisons of cultural and clinical findings have been made as in the present paper, the Michigan group (4-1), Jay (24), Rosebury and Greenberg (25), Enright, Friesell and Trescher (26), and others, a correlation between the numbers of lactobacilli and the caries observed in the subjects may be demonstrated. Yet in any group, even as in the present selected caries-free children, cultures of the salivas will show certain individuals who are either consistently positive or negative for lactobacilli, some who are becoming free from lactobacilli, and others in whose mouths lactobacilli are beginning to appear. On a clinical basis these results would be interpreted as definite caries or caries expectancy for the continued or intermittent positives, and freedom from decay for the negatives or those subjects entering a lactobacillus free period. Using the numbers of lactobacilli as an index, Jay (33) feels able with reasonable accuracy to forecast the expectancy of new or recurrent caries.

In this study the Maumee group of 17 children remained on the whole free from lactobacilli and caries. One child with no lactobacilli in the specimens of saliva cultured was found to have a slight extension of a previous lesion at the dental examination 3 months after the last saliva sample was taken. The possibility of extension in that time interval makes this exception of doubtful significance. One other child had numerous lactobacilli at every examination but no caries. The low incidence of caries in this home in spite of a caloric and vitamin deficient diet is remarkable. The seemingly important factor in their diet is the nearly complete absence of refined sugar. As long as the children are in the home, they remain usually free from 
lactobacilli and caries is practically non-existent. That these individuals are not naturally resistant or immune to caries may be discerned from the candy feeding experiments recorded by Jay, Hadley, Bunting and Koehne (34), and by the fact that many of these children had caries previous to entering the home.

Of the 21 Ann Arbor children selected as caries-free, dental information was available for only 18 at the middle and end of the period. Six children had definite caries associated with significant lactobacillus counts. Three had no caries but their salivas usually contained appreciable numbers of lactobacilli. Five were negative for lactobacilli and were free from caries activity. The remaining 4 showed sporadically positive salivas but were caries-free. The concluding dental and bacteriological examinations showed, therefore, a fair amount of caries and a tremendous increase in the occurrence of lactobacilli in the saliva. For those individuals with no caries and persistent lactobacilli in the saliva, the necessity for further observation is obvious.

Among the other acidogenic or aciduric forms isolated or observed, the staphylococci and sarcines were apparently eliminated from consideration because they were about equally distributed in carious and non-carious mouths. The streptococci did not seem to have any relation to the caries observed, since there were more streptococci from the salivas of the caries-free Maumee children than from the Ann Arbor group which was not caries-free. Although Anderson and Rettger (16) showed that streptococci decalcified the enamel of teeth in vitro and felt that streptococci should not be disregarded in the caries problem, it can hardly be said that the conditions of the test tube are duplicated in the mouth. For a detailed review of the problems of in vitro decalcification in relation to the disease the admirable paper of Enright, Friesell and Trescher (26) should be consulted. These workers arrived at the conclusion that lactobacilli were the most important bacteria involved in dental caries, but they are quoted incompletely and to the contrary by Anderson and Rettger. Furthermore, our experience, as well as others, has been that when cultures of saliva or teeth are made in glucose broth or glucose brain broth the streptococci always present will grow very rapidly but will shortly decrease in numbers under the acid produced and will be 
overgrown by the lactobacilli if present. This situation unquestionably explains Tunnicliff and Hammond's recovery of bacilli which they assumed to be rough variants of streptococci, from glucose broth cultures of dentin and pulps. The impurity of their cultures is all the more emphasized by the isolation of streptococci from the bacilli after several rapid transfers but inability to do the same with pure line strains of $L$. acidophilus. Their conclusion that streptococci were the invaders in dental caries no matter what the predisposing factors was weakened also by the fact that their cultures were limited to 6 pulps, 6 dentins, and 2 specimens of saliva.

The yeasts provoked interest because they were the only organism present in significant numbers in the mouth of the Maumee child with an extension, and they were also found frequently in 3 of the 6 Ann Arbor children with caries. These observations bring up the work of Fosdick and Hansen (42) who found that the rate of calcium disintegration in saliva and carbohydrate mixtures increased 100 per cent by the addition of yeasts to the lactobacillus cultures. Thus, it is probable, that while yeasts do not under ordinary circumstances cause tooth decay, they hasten the process. In such a way the problems of synergism are presented by the legion and variety of bacteria in the mouth and the combined action of their end products about which we have little or no information.

\section{SUMMARY}

The occurrence of lactobacilli in the salivas of selected caries-free children was observed over an 18 month period. In the salivas of 17 children from an institution in Maumee, Ohio, only 11 of 159 specimens were positive for lactobacilli, whereas of 178 specimens of saliva from 21 Ann Arbor public school children 85 were positive for lactobacilli. Similarly, the teeth at the end of the study showed only 1 Maumee subject to have a small extension, the significance of which was questioned, while 6 Ann Arbor children were definitely subject to caries. Although as individuals there were several apparent exceptions, as the one Maumee and several Ann Arbor subjects who had lactobacilli more or less consistently present in their salivas but had no caries, it must be remembered that these children were carefully selected as caries-free in the beginning and did not represent a cross- 
section study. It is obvious that further individual studies should be made. Nevertheless, as groups divided on the basis of lactobacillus population, those children who had no lactobacilli in their salivas at the time of collection remained free from caries, and those who had significantly appreciable numbers of lactobacilli in the saliva showed varying amounts of decay. Other aciduric organisms were isolated, but of the yeasts, streptococci, and staphylococci only the yeasts seemed to have any relation to the caries observed and this role was apparently secondary to that played by the lactobacilli.

\section{REFERENCES TO LITERATURE}

1. MILLer, W. D., Die Mikroorganismen der Mundhöhle. (Leipzig, George Thieme: 1889.)

2. KuIGLER, I., J. Allied D. Assoc., 10: 141, 282, 445, 1915.

3. RodRIGUEZ, F. E., Military D. J., 5: 199, 1922.

4. Bunting, R. W., ANd Palmerlee, F., J. A. D. A., 12: 381, 1925.

5. Bunting, R. W., Nickerson, G., ANd Hakd, D. G., D. Cosmos, 68: 931, 1926.

6. Bunting, R. W., Nickerson, G., Hard, D. G., ANd Crowley, M., D. Cosmos, $70: 1$, 1928.

7. Bunting, R. W., Hadley, F. P., Jay, P., And Hard, D. G., Am. J. Dis. Child., 40: 536, 1930.

8. Bunting, R. W., Nickerson, G., Hard, D. G., and Kelier, M., D. Cosmos, 70 : $1002,1928$.

9. Hadley, F. P., Bunting, R. W., And Delves, E. A., J. A. D. A., 17: 2041, 1930.

10. HadLEY, F. P., AND Buntrng, R. W., J. A. D. A., 19:28, 1932.

11. Koemen, M., Bunting, R. W., AND Morreli, E., Am. J. Dis. Child., 48: 6, 1934.

12. MoRIsHTA, T., J. Bact., 18: 181, 1929.

13. Rettger, L. F., AND Horton, G. D., Centbl. f. Bakt., 73: 362, 1914.

14. Hunt, G. A., AND RetTGer, L. F., J. Bact., 20: 61, 1930.

15. Weinstein, L., Anderson, T. G., ANd RetTger, L. F., J. D. Res., $13: 323,1933$.

16. ANDerson, T. G., AND Retrger, L. F., J. D. Res., 16: 489, 1937.

17. GOADBY, K., Brit. Med. J., $2: 769,1910$.

18. ClaAk, J. K., Brit. J. Exp. Path., 5: 141, 1924.

19. BAUMGARTNER, E., Wien. kl. Woch., 26: 178, 1913.

20. Kantorowicz, S., Deut. Zahn., 21 : 3, 1911.

21. Hartzeli, T. B., AND HenRTCI, A. T., J. N. D. Assoc., 4: $477,1917$.

22. TunNicliff, R., AND Hammond, C., J. A. D. A., 25: 1047, 1938.

23. McIntosh, J., James, W., and Lazarus-Barlow, P., J. Brit. D. Assoc., 43: 728, 1922.

24. JAY, P., J. A. D. A., 16: 230, 1929.

25. RosebURy, T., AND GREENBERG, S., J. D. Res., 12: 430, 1932.

26. ENRIGHT, J. J., Frieseli, H. E., AND Trescher, M. O., J. D. Res., 12 : 759, 1932.

27. TUCKER, W. H., J. Inf. Dis, 51 : 444, 1932.

28. Johnston, M. M., KaAkE, M. J., AND AGNEw, M. C., J. A. D. A., 20: 1777, 1933. 
29. NizzLE, A., Handbuch der pathogenen Mikroorganismen. Kolle-Wassermann, 6: 391, 1929.

30. Crutcishank, J., and Cruickshank, R., System of Bact., 8: 334, 1931.

31. Johnston, M. M., Williams, C. H. M., Anderson, P. G., Drake, T. G. H., TisDALI, F. F., AND KAaKE, M. J., J. A. D. A., $23: 1493,1936$.

32. Hadley, F. P., J. D. Res., $13: 415,1933$.

33. JAY, P., Bacteriology and Immunology of Dental Caries. Dental Science and Dental Art., Gordon, S. editor., (Phila. Lea \& Febiger: 1938).

34. Jay, P., Hadley, F. P., Bunting, R. W., and Koehne, M., J. A. D. A., 23: 846, 1936.

35. Fosdick, L. S., and Hansen, H. L., J. A. D. A., 23 : 401, 1936. 